\title{
A FUZZY LOGIC MODEL FOR ZONE DELINEATION IN A PRESERVATION AREA IN BRAZIL
}

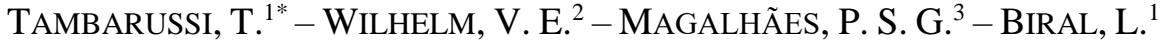 \\ ${ }^{1}$ Federal University of Technology - Paraná, 85892-000 Santa Helena, PR, Brazil \\ ${ }^{2}$ Federal University of Paraná, PO Box 19011, 81531-990 Curitiba, PR, Brazil \\ ${ }^{3}$ Federal University of Technology - Paraná, 85884-000 Medianeira, PR, Brazil \\ *Corresponding author \\ e-mail: tambarussi@utfpr.edu.br; phone: +55-45-3268-8807; fax: +55-45-3268-8800
}

(Received 14 ${ }^{\text {th }}$ Dec 2018; accepted $27^{\text {th }}$ Feb 2019)

\begin{abstract}
Territorial planning plays a fundamental role in preservation of areas for ecological conservation and environmental management as well as in providing adequate spaces for visitation and research and prioritizing sustainable relationships between man and nature. The present work exhibits a methodological proposal that allows the standardization of territorial classifications in preservation areas. Based on fuzzy logic, the proposed model observes the particularities of a preservation area; hence, the decision generated in the classification of zones represents the work that is currently being developed in the areas of biology, geography, environmental engineering, among other research groups. The modeling combines the evaluation of the data collected in the field (variables: quantitative and qualitative) with vegetation indices obtained from satellite imagery. Combining this information enables each sampling point to be categorized, thereby generating preservation area zones. The results showed that the methodology can distinguish border areas as transition zones, allowing appropriate management to offer detailed information of the study area. The case study, in which the methodology was applied in a preservation area in southern Brazil, showed that the methodology assists in territorial planning, with a clear indication of what actions have been performed and simple data collection.
\end{abstract}

Keywords: environmental preservation, southern Brazil, standardized classification, territorial planning, zone of transition

\section{Introduction}

The recent decades have seen a growing discussion by political authorities and scholars regarding the need to delimit natural areas for conservation and increased coverage and effectiveness of protected areas (Watson et al., 2014). The meaning of sustainability is often debated, which can be conceptualized as the management of resources such that their contribution to human welfare is conserved or improved for the next generations (Kennedy, 2007). Brazil, with its vast territory of more than 8.5 million $\mathrm{km}^{2}$ (IBGE, 2019), is responsible for protecting its natural environment, which is a difficult task when facing pressures for the expansion of land use for economic purposes, such as agriculture, pasture, and mining (IBGE, 2015). From 2003 to 2009, Brazil stood out in relation to the expansion of the network of preservation areas (PA). Brazil accounts for $73 \%$ of world expansion out of the entire legally protected area of the planet that was established in 2003 (Jenkins and Joppa, 2009).

In Brazil, PAs are called conservation units; hence, the designation to the National System of Nature Conservation Units (SNUC in Portuguese) established in 2000 by federal law aims to ensure that all conservation units represented significant ecological samples from different populations, safeguarding the existing biological patrimony 
(Ministério do Meio Ambiente, 2011; Bernard et al., 2014). In 2002, the Brazilian government established several procedures and criteria for the creation of each PA, establishing its management plan, protection, and supervision actions that must be formalized and implemented. The management plan is a document that works as the identification of the area of preservation, having the zoning definition of a PA observing the particularity of each zone as a fundamental part with adequate management to the territorial ordering, such that the administration of the entire of the area reaches objectives with consistency and effectiveness. Although the legislation deals with zoning, the distinction between legislation and scientific knowledge is still quite high (AzevedoSantos et al., 2017). The process of how to do this territorial division is guided by documents with a methodological superficial purpose; however, when we looked for this information in the management plans, we observed that zoning occurs in different ways because no methodology standardizes this classification.

In terms of the effectiveness of classification, many questions can still be asked regarding zoning in preservation areas. Liu and Li (2008) highlighted several known problems with the implementation of zoning schemes in China and elsewhere, including the lack of clear regulations on how to structure the spatial arrangement of zones and the lack of guidelines that determine the factors that should be considered since the creation of the PAs (Fendrich et al., 2019).

In study by Lima and Ranieri (2018), zoning can be approached in many ways. Land use planning is done with respect to only one type of zone. The study was done through a documentary analysis using the management plans. Zhang et al. (2013) used the methodology of combining interviews with geographic information systems (GIS) using a multi-criteria decision analysis based on the GIS method to formulate the zoning areas in the national park, with a wise process used to identify the priorities and prior knowledge of the area. Interviews were then conducted for the case study. The study of Vardarman et al. (2018) observed that the invasion of exotic species generated a zoning according to the degree of invasion by making field observations and performing statistical analyses. The main source of data for spatial delimitation of maps was provided by a nature conservation agency in the Czech Republic.

A natural phenomenon related to sustainability can be described in many ways, including visualization, physical models based on the creation or recreation of ecosystems, and conceptual and quantitative models. The last method, where the fuzzy logic theory can be applied, is the most informative for decision makers (Todorov and Marinova, 2011). An eminent factor of the fuzzy logic theory is the ability to capture intuitive concepts in addition to considering the psychological aspects used by humans in their usual reasoning; this has not been represented in traditional models (Zadeh, 1965; Oliveira, 1999; Zimmermann, 2001).

Multi-criteria analyses are examples of techniques that consider several perspectives and can integrate several actions in the decision process in a certain complex situation. From the operational point of view, multi-criteria methods have the ability to adapt to problems on several fronts, which can be described as conflicting interests. Although the multi-criteria evaluation technique does not solve the problem, it can help detail the problem, making the complex situation more transparent for decision makers (Munda et al., 1994; Hsueh and Cheng, 2017).

The objective of this study was to develop a quantitative model based on fuzzy logic to delineate the management zones in PA in Brazil. For this purpose, the possible variables (i.e., quantitative and qualitative) must be combined such that the map of the 
area emphasizes its relationship with the surrounding areas. A case study was performed in a PA in southern Brazil to test the efficiency of the model.

\section{Materials and Methods}

\section{Preservation area establishment}

The establishment of all possible zones for a Brazilian PA covers the following: zone intangible, natural, extensive use, intensive use, historical-cultural, recovery, special use, conflicting use, temporary occupation, indigenous superposition, experimental interference, buffer, and presented in the Methodological Guideline according to the national legislation (IBAMA, 2002; Mazza et al., 2016; Simardi and Souza, 2018).

A PA can be classified in two ways. Some PAs need only a specific element for their classification (e.g., in the case where buildings are identified, the PA is automatically classified as a "zone of special use"). These zones in PAs include zones of special use, zones of conflicting use, zones of temporary occupation, indigenous superposition, and zones where historical/cultural heritage is found (Fig. 1).

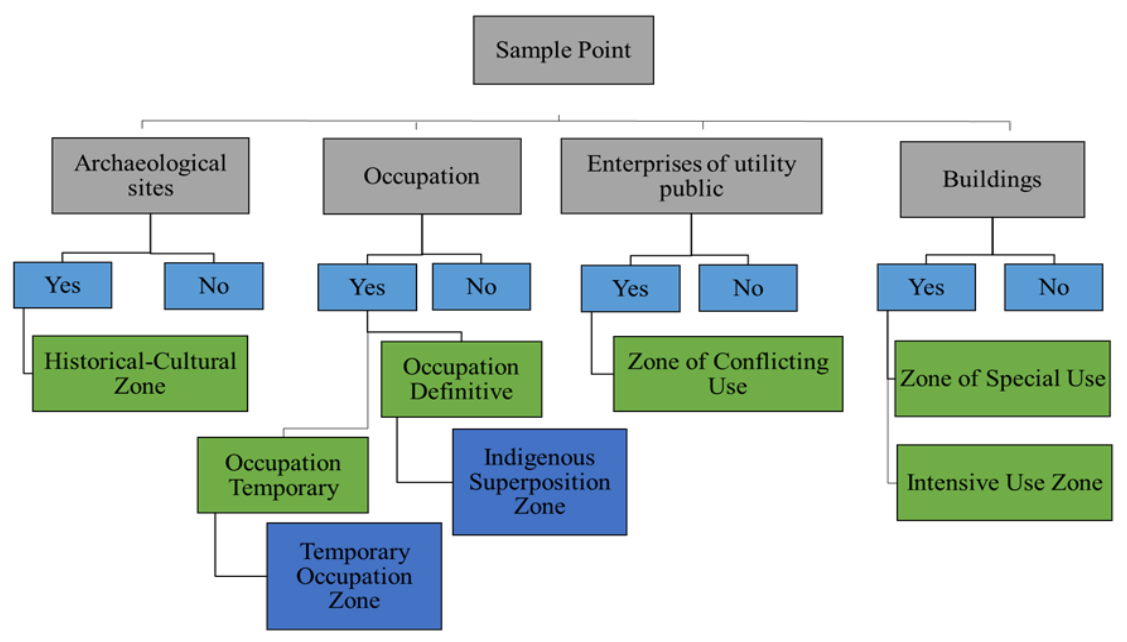

Figure 1. Scheme for the classification of areas with specific characteristics

However, such specific elements will not always appear to generate the classification, which makes it necessary to seek the criteria for classifying intangible zone (IZ), natural zone (NZ), extensive use zone (EUZ), and recovery zone (RZ). The classification of this second group of PAs is much more complex and relies on the criteria not always clear for a decision maker.

\section{Study area and data}

The study area is the Santa Helena Relevant Ecological Interest Area (ARIE-SH), a 1.515 ha preservation area in the phytogeographic domain of the Atlantic Forest, which, in ecology, is considered a hotspot (Myers et al., 2000). According to the Brazilian legislation, this PA is classified as a Relevant Ecological Interest Area, a permanent category to sustainable use, with characteristics of possessing small areas with little or no human occupation and a singular natural feature with the purpose of protecting local ecosystems. 
ARIE-SH is located in the southern region of Brazil in the municipality of Santa Helena, state of Paraná (Fig. 2). It was officially established in 1984 on the banks of the Paraná River at the border between Brazil and Paraguay after the construction of the hydroelectric power plant of Itaipu (Management Plan, 2010).

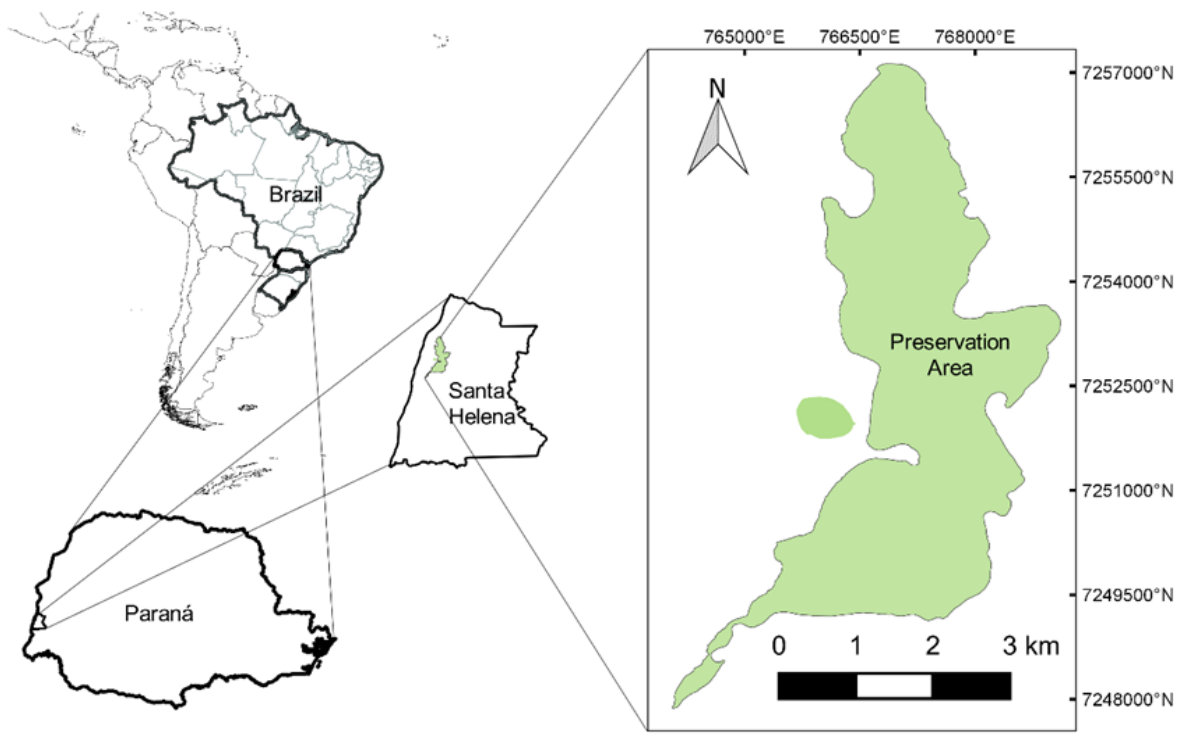

Figure 2. Location of the Santa Helena Relevant Ecological Interest Area (images projected in the Universal Transverse Mercator (UTM) projection zone 21S and WGS 84 (World Geodetic System 84) ellipsoid)

At this time, many areas along the river were expropriated, and reforestation with exotic and native trees species took place. Nowadays, the ARIE-SH is covered by a semideciduous seasonal forest according to the Brazilian classification of vegetation provided by IBGE (2012) in different stages of ecological succession. The main exotic species present include mango (Mangifera indica L.), jambolão or Java plum (Syzygium cumini (L.) Skeels), and Japanese raisin tree (Hovenia dulcis Thunb.). Meanwhile, the areas, where native species were planted, show a high diversity with several native herbaceous and shrub species, including ferns, growing in the shade subforest. The areas, where native species were planted, such as pitanga or Surinam cherry (Eugenia uniflora L.) and gabiroba (Campomanesia xanthocarpa Mart. ex O. Berg), are the richest in the number of trees species and present an intermediate successional stage.

Fieldwork was performed between March 2018 and June 2018. A total of 87 plots measuring $5 \times 10 \mathrm{~m}^{2}$ were sampled using the method proposed by Muller-Dombois and Ellenberg (1974). The location of the plots was selected with a distance of approximately $400 \mathrm{~m}$. During the survey, the circumference at breast height $(\mathrm{CBH})$ parameter was used in reference to the circumference of the trunk at $1.30 \mathrm{~m}$ height. Each plot was georeferenced at its center point using a global navigation satellite system (GNSS) (Etrex 30, Garmin, Garmin International, Inc., Kansas City, USA) receiver with a positional accuracy of approximately $5 \mathrm{~m}$. The vegetation data collected in each plot consisted of (a) the number of trees with a $\mathrm{CBH}$ greater than or equal to $0.30 \mathrm{~m}$, (b) the diversity of species, that is, how many species have a CBH greater than or equal to $0.30 \mathrm{~m}$, and (c) the regeneration level registered by photography. 


\section{Model structure}

The interpretability of the classification systems refers to their ability to express their behavior in a manner that is easily understood by a user (Jim and Mart, 2019). Based on this indication and to find means of facilitating the systematization of the process, a model was developed to propose to classify the sampled areas. The chosen variables were based on vegetation because "the lower degree of degradation of vegetation generally leads to the lower degree of degradation of fauna and soils" (IBAMA, 2002).

The input variables for the study are as follows: vegetation density index, diversity of species, and regeneration index. The expected output variable refers to "zoning," where each investigated point will be associated with a zone. The general approach is to first quantify the linguistic statement then retransmit the quantized logical input and output ratios using mathematical operators (Chen and Pham, 2000).

The fuzzy sets for the input and output variables considering the working hypothesis can be represented in several ways by pertinence functions, the most common being the triangular, trapezoidal, Gaussian, bell-shaped, Z-shaped, and S-shaped functions (Ibrahim, 2004). The pertinence functions chosen to describe the variables in this work exclude the triangular and trapezoidal functions considering that in nature, the behavior changes are not abrupt.

The membership function in the " $Z$ " form is presented as follows:

$$
f(x, a, b)=\left\{\begin{array}{lc}
1, & x<a \\
1-2\left(\frac{x-a}{b-a}\right)^{2}, & a \leq x<\frac{a+b}{2} \\
2\left(\frac{b-x}{b-a}\right)^{2}, & \frac{a+b}{2} \leq x<b \\
0, & x \geq b
\end{array}\right.
$$

The membership function in a bell shape is:

$$
f(x, a, b, c)=\frac{1}{1+\left|\frac{x-c}{a}\right|^{2 b}}
$$

The membership function in the " $\mathrm{S}$ " form is presented as:

$$
f(x, a, b)=\left\{\begin{array}{lr}
0, & x<a \\
2\left(\frac{x-a}{b-a}\right)^{2}, & a \leq x<\frac{a+b}{2} \\
1-2\left(\frac{x-b}{b-a}\right)^{2}, & \frac{a+b}{2} \leq x<b \\
1, & x \geq b
\end{array}\right.
$$

\section{Input variable: "Vegetation density index"}

The vegetation density index (VDI) is described by the membership function considered in the range of 0 to 10 , with the low, medium, and high linguistic denominations (Fig. 3). It could have been chosen from 0 to 1 or from 0 to 5 provided that the membership functions were allocated at intervals consistent with its name. 
The membership function with a "low" denomination is a Z-shaped function (Eq. I) with $f(x, 1.5,5)$. The term "medium" is described by a bell-shaped function $(E q .2)$ with $f(x, 1.5,3,5)$. Finally, the membership function described by the linguistic term "high" vegetation concentration has an $\mathrm{S}$ form $(E q .3)$ with $f(x, 5,8.5)$.

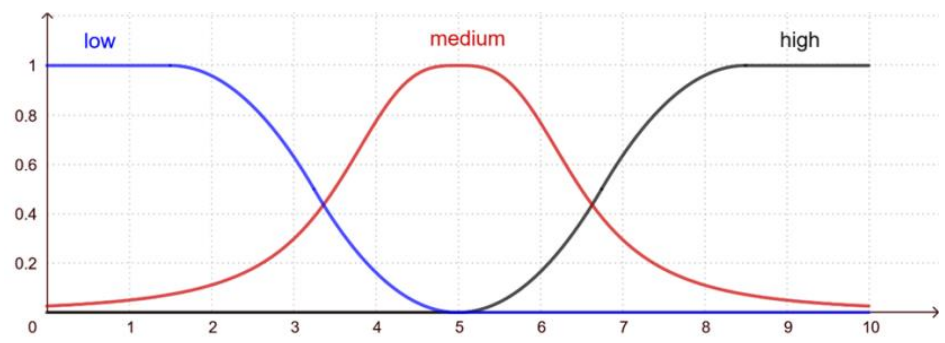

Figure 3. Membership functions describing the vegetation concentration

The VDI of the $i$ th sampling plot is calculated as follows (Eq. 4):

$$
V D I_{i}=\left[\frac{\left(E V I_{i}+N T_{i}\right)}{\max _{1 \leq j \leq n}\left\{E V I_{j}\right\}+\max _{1 \leq k \leq n}\left\{N T_{k}\right\}}\right] \cdot 10
$$

where $E V I_{i}$ is the result obtained by the index of vegetation between -1 and 1, which can be searched for in the software by georeferenced points; $N T_{i}$ is the number of trees in the $i$ th sampling plot; $\max _{1 \leq k \leq n}\left\{N T_{k}\right\}$ is the maximum number of trees observed among all the sampling plots $(\mathrm{k}=1,2,3, \ldots, 87)$; and $\max _{1 \leq j \leq n}\left\{E V I_{j}\right\}$ is the maximum enhanced vegetation index (EVI) observed and calculated for each point sampled in the study area $(j=1,2,3, \ldots, 87)$.

With regard to remotely mapping disturbances and land use/land cover (LULC), the data from the satellite-based sensors have proven useful for large-area characterization (Atzberger, 2013). The EVI will be used as input in the fuzzy system. The EVI is an "optimized" vegetation index designed to improve the vegetation signal with better sensitivity in regions of high biomass and vegetation monitoring (Eq. 5) (Jensen, 2009).

$$
E V I=G \frac{\rho_{\text {nir }}-\rho_{\text {red }}}{\left(\rho_{\text {nir }}+C_{1} \rho_{\text {red }}+C_{2} \rho_{\text {blue }}+L\right)},
$$

where, $\rho_{\text {nir }}$ is the reflectance in the near infrared band $(0.73 \mu \mathrm{m}) ; \rho_{\text {red }}$ is the reflectance in the red band $(0.66 \mu \mathrm{m}) ; L$ is a soil adjustment factor; and $C_{1}$ and $C_{2}$ are the coefficients describing the use of the blue band for the correction of the red band for atmospheric scattering by aerosols. These coefficients were empirically determined as $L=1, C_{1}=6$, $C_{2}=7.5$, and $G$ (gain factor) $=2.5$ (USGS, 2017). The Landsat 8 images used in this work were accessed by the United States Geological Survey (USGS) search platform in March 8, 2018. 


\section{Input variable: "Diversity of species"}

Data collection was designed to survey the variety and quantity of the plant species present on the site. The methodological guideline states that areas with the greatest number of species found should integrate the zones of greater degree of protection, such as the intangible and natural zones. For the variable "diversity of species," the membership function with a "low" qualification is a function in $\mathrm{Z}$ form with $f(x, 1.5,5)$. The linguistic term "medium" is described by the bell-shaped function $f(x, 1.5,3,5)$, while the term "high" is described by the S-shaped function with $f(x, 5,8.5)$.

The diversity of tree species at the $i$ th sampling plot, $D T E_{i}$ was calculated using the following formula:

$$
D T E_{i}=\left(\frac{N E_{i}}{\max _{1 \leq l \leq n}\left\{N E_{l}\right\}}\right) \cdot 10
$$

where $N E_{i}$ is the number of tree species observed in the $i$ th sampling plot, and $\max _{1 \leq l \leq n}\left\{N E_{l}\right\}$ is the maximum number of tree species found among all sampling plots. The output was multiplied by 10 to scale the values between 0 and 10 .

\section{Input variable: "Regeneration index"}

The input variable "regeneration index (RI)" is the variable considered in the characterization of zoning because it is a reforestation area. The classification of regeneration provides information that will be considered in the model. The linguistic denominations in the variable regeneration were low, medium, and high (Fig. 3).

To distinguish between terms, an area with a mean vegetation that did not enter the sample was considered as high regeneration because it did not complete the $0.30 \mathrm{~m}$ diameter that was considered. The term linguistic medium regeneration considered areas with a low and sparse vegetation, among others. The term "low regeneration" was used in places without vegetation in the sub-forest layer.

The membership function with the "low" qualification is a function in $\mathrm{Z}$ form $(E q .1)$ with $f(x, 1,5)$. The function with the "medium" qualification is expressed by the bellshaped function with $f(x, 1.5,1.5,5)$. Meanwhile, the function with the "high" qualification is expressed by the function with an $\mathrm{S}$ form with $f(x, 5,9)$.

\section{Output variable: "Zoning"}

The output variable "zoning" has four membership functions: IZ, NZ, EUZ, and RZ (Fig. 4).

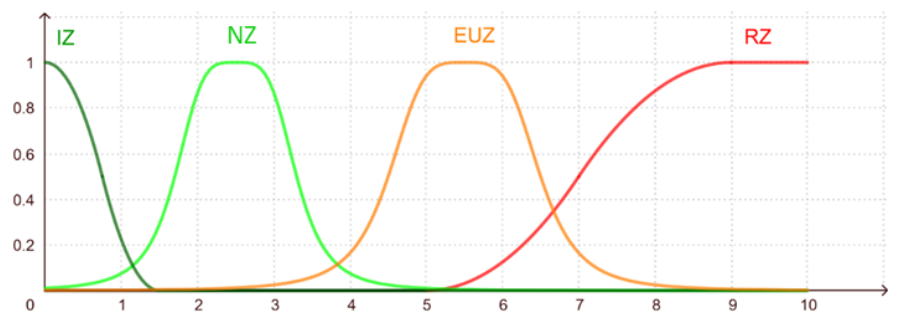

Figure 4. Membership function of the output variable "zoning" 
The membership function that represents IZ is a function in the $\mathrm{Z}$ shape with $f(x, 0,1.5)$. The membership function for $\mathrm{NZ}$ is associated with the bell-shaped function with $f(x, 0.8,2,2.5)$. The EUZ is also associated with the bell-shaped function with $f(x, 1,2,5.5)$. Finally, the membership function that describes RZ is a function in the $\mathrm{S}$ shape with $f(x, 5,9)$.

\section{Base rule}

This phase is the construction of the base rule that directly interferes with the result, which is still subjective and handmade (Rezende, 2005). Many efforts have been made to systematize or even automate the process of acquiring knowledge. In fuzzy systems, the semantics formed by the operators play a deterministic role.

The base rule is a statement of fuzzy rules in the form of if-then. A general approach would be to first quantify the linguistic statement then retransmit the quantized logical input and output ratios using the mathematical operators (Chen and Pham, 2000). In this work, the operator "and" will be used with the Mamdani controller defined as $I_{c}(x, \mu(x))=\min \{x, \mu(x)\}$ (Zimmermann, 2001). The operator "and" is used with Mamdani (Fig. 5) when listing the input variables.

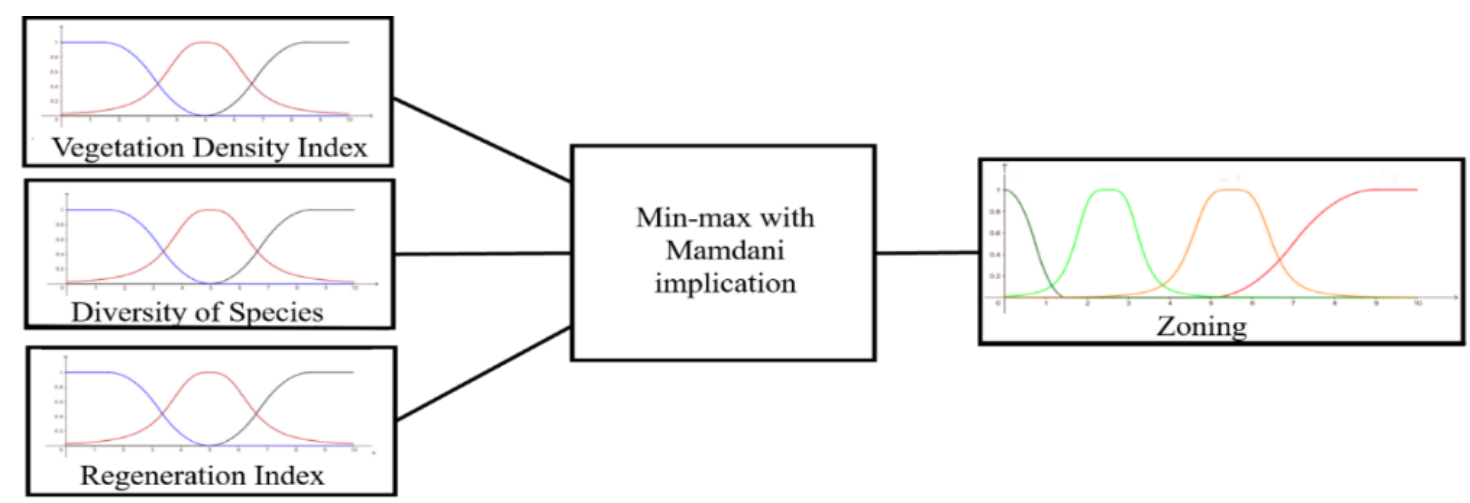

Figure 5. Fuzzy system scheme for the proposed model

The base rule in the proposed model will combine the input variables according to its attributes, thereby obtaining 27 rules (Table 1).

Table 1. Rules for zoning delineation

\begin{tabular}{c|c|c|c|c|c|c|c}
\hline \multirow{2}{*}{$\mathrm{n}^{\text {o }}$} & \multicolumn{5}{|c|}{ Input variables } & \multicolumn{2}{c}{ Output variables } \\
\cline { 2 - 7 } & $\begin{array}{c}\text { If vegetation } \\
\text { concentration }\end{array}$ & and & $\begin{array}{c}\text { if species } \\
\text { diversity }\end{array}$ & and & if regeneration & then & zoning \\
\hline 1 & low & and & low & and & Low & then & $\mathrm{RZ}$ \\
2 & medium & and & low & and & Low & then & $\mathrm{RZ}$ \\
$\ldots$ & low & and & medium & and & Low & then & $\mathrm{RZ}$ \\
10 & medium & and & medium & and & Low & then & EUZ \\
11 & medium & and & high & and & High & then & $\mathrm{NZ}$ \\
$\ldots$ & high & and & high & and & High & then & $\mathrm{IZ}$ \\
\hline
\end{tabular}




\section{Fuzzy inference}

The information regarding the RI were observed for each sample point. $V D I_{i}$ and $D T E_{i}$ were also calculated according to (Eq. 4) and (Eq. 6), respectively. The input value in the fuzzy system will be a point with three coordinates, which generates a real number as a result, using the gravity center defuzzification method (GCD) (Gomide and Gudwin, 1994; Zimmermann, 2001) (Eq. 7):

$$
G C D=\frac{\int_{a}^{b} x \mu(x) d x}{\int_{a}^{b} \mu(x) d x}
$$

In the GCD, $[a, b]$ is the range of coverage of the membership functions, which in this case is $[0,10]$. Considering the area formed by the contribution of all the rules, $(E q .7)$ considers the degree of pertinence (weight) of each point inserted in the model, consequently obtaining a real number as a result. This method returns the point representing the center of the area (or gravity) under the curve formed by the output membership function. The sampled point was classified according to the zone established depending on the GCD output value (Table 2).

Table 2. Zoning classification according to the GCD range

\begin{tabular}{c|c}
\hline Zone & GCD range \\
\hline Intangible & 0 to 1.5 \\
Natural & 0 to 5.0 \\
Extensive Use & 2.0 to 9.0 \\
Recovery & 5.0 to 10.0 \\
\hline
\end{tabular}

Each sampled point will be at the intersection of two fuzzy sets representing the zoning. The set for which the point has the highest degree of pertinence will be considered in their classification. If this point is exactly at the intersection point of the pertinence functions, this point will be classified in the most restrictive zone.

\section{Interpolation}

The inverse distance weighted (IDW) interpolation method (Eq. 8) (Shepard, 1968) was used to generate the thematic maps with the results of the case study applied to the model proposed in this work. Several powers were tested (i.e., 1, 2, 3, 4, 5, and 10). The one with the lowest mean error in the cross-validation was chosen.

$$
X_{p}=\frac{\sum_{i=1}^{n} \frac{1}{d_{i}^{p}} \cdot X_{i}}{\sum_{i=1}^{n} \frac{1}{d_{i}^{p}}}
$$

where, $X_{p}$ is the interpolated variable; $X_{i}$ is the value of the variable for the $i$ th neighbor; $d_{i}$ is the Euclidean distance between the $i$ th neighborhood point and the sampled point; and $p$ is the power of the distance. 


\section{Results}

The model presented an efficacy in classification, coherence between the surrounding areas, and in describing the area as observed in the fieldwork in conformity to the area documents (Management Plan, 2010). The results obtained using the model for zoning delineation in ARIE-SH allows classifying the 87 sampled points in the area in accordance to the PA defined by IBAMA (2002). The samples were classified in the range of 0.51 to 8.29 in accordance with the proposed methodology with an average of 4.70 and a CV of 0.43 . The average parameters permeated the area as an "Extensive Use Zone." The IDW (power 2) interpolated thematic map (Fig. 6a) represents the area divided in four zones (Table 3). The transition areas between the zones (i.e., IZ and NZ, NZ and EUZ, and EUZ and RZ) were created by observing the coverage range (Table 2) of each pertinence function for the output variable (zoning) (Fig. 6b). The values obtained in these intervals were considered as transition regions, which may belong to zones with different degrees of pertinence (Table 4).

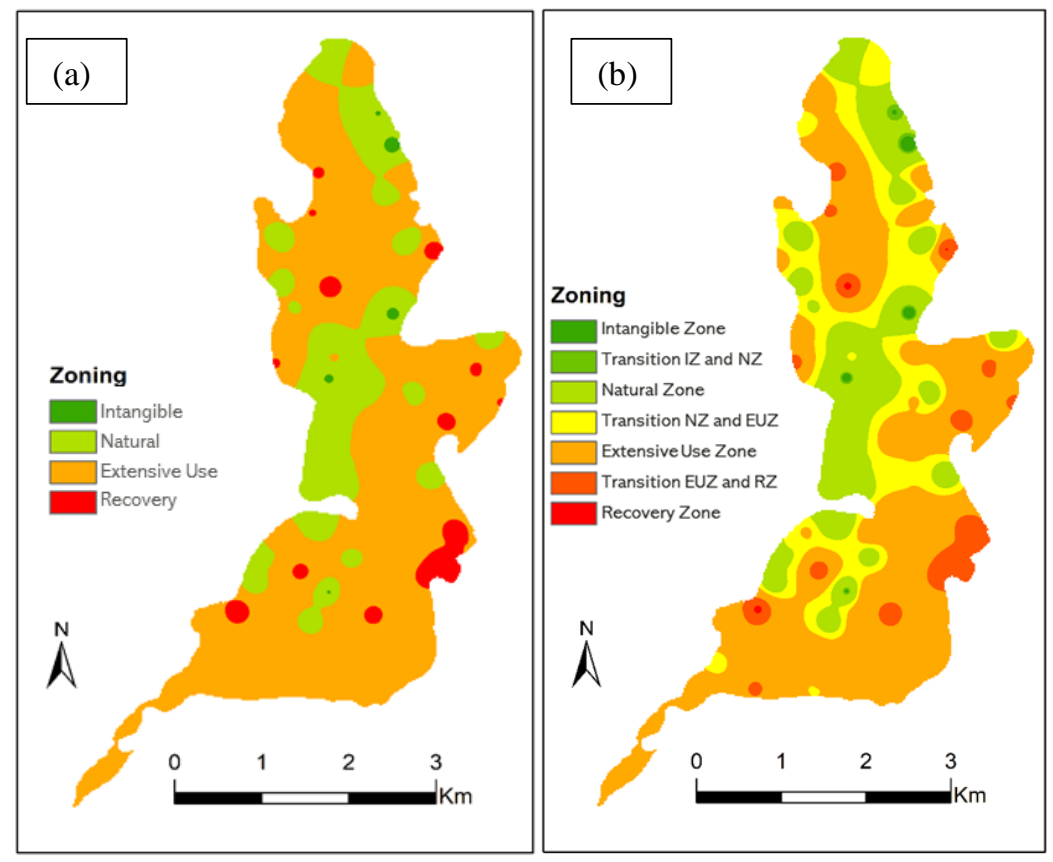

Figure 6. Zoning map of the area with the proposed methodology: (a) area divided in four zones and $(b)$ area considering the regions of transition between one zone and another

Table 3. Area of each zone considering the PA classification (IBAMA, 2002)

\begin{tabular}{c|c|c}
\hline Zone & Area (ha) & Area (\%) \\
\hline Intangible IZ & 2.47 & 0.16 \\
Natural NZ & 339.63 & 22.41 \\
Extensive Use EUZ & 1123.2 & 74.09 \\
Recovery RZ & 50.60 & 3.34 \\
\hline
\end{tabular}

The cross-validation performed for the PA classification produced a correlation coefficient of 0.2429 , which was evaluated as poor (values under 0.5 ), moderate to good 
(values from 0.50 to 0.75 ), and excellent (values above 0.75 ). The root mean square error (RMSE) was 1.99. The mean error (ME) was 0.0136 (Fig. 7).

Approximately $74.09 \%$ of the area extension belonged to the Extensive Use Zone, $0.16 \%$ to the Intangible Zone, $22.41 \%$ to the Natural Zone, and $3.34 \%$ to the Recovery Zone (Table 3). When zoning was distributed, including the transition areas, a more detailed understanding of the area can be achieved (Table 4). The natural zone that occupied $22.41 \%$ of the original map was reduced to $21.91 \%$, but allowed the observation of a larger area (19.25\%) that can be classified as a transition area between NZ and EUZ. This result indicated that this area can receive an adequate management to integrate the Natural Zone in the future.

Table 4. Area of each zone considering the transition zone for PA

\begin{tabular}{c|c|c}
\hline Zone & Area (ha) & Area (\%) \\
\hline Intangible IZ & 2.47 & 0.16 \\
Transition IZ and NZ & 7.55 & 0.5 \\
Natural NZ & 332.07 & 21.91 \\
Transition NZ and EUZ & 291.87 & 19.25 \\
Extensive Use EUZ & 831.32 & 54.84 \\
Transition EUZ and RZ & 50.60 & 3.34 \\
Recovery RZ & 0 & 0 \\
\hline
\end{tabular}
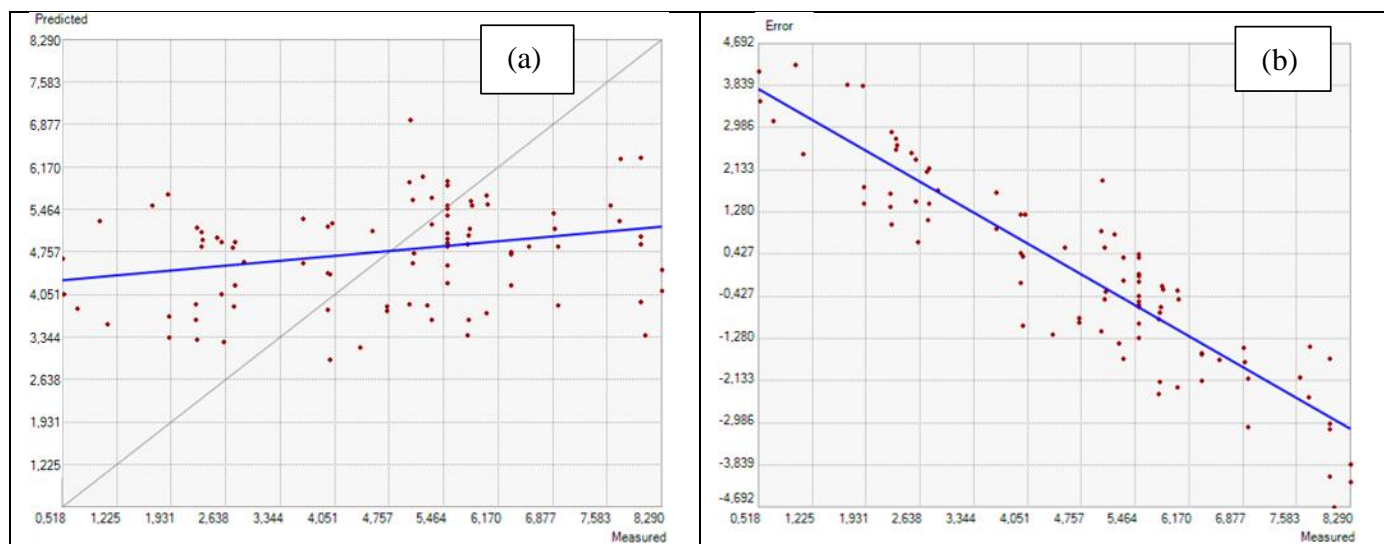

Figure 7. Adjustment of the points evaluated in the interpolation: (a) fit for the interpolated data with a regression equation of $0.114 x+4.23$ and $(b)$ error in the prediction with a regression equation of $-0.885 x+4.23$

\section{Discussion}

The model presents allows decision makers to classify the PA in a reasonable zoning scheme and enables it to be adjusted to any biome by observing the input variables. This classification generates reliability to the process that becomes standardized. Our model was able to describe the study area using quantitative (i.e., VDI and diversity of tree species) and qualitative (regeneration) variables because of the fuzzy logic that allows us to describe the variable flexibility; hence, it has been used to model landscapes and in different ecological and environmental studies (Sheehan and Gough, 2016).

In the case of a complex system (e.g., natural reserves), we have a model generating several zones based on measurable variables that present ease in the field work, not 
generating great distortions according to the specialist who will reproduce the zoning. Moilanen et al. (2009) argued that a major limitation in land-use planning when made by software is the inability to consider different zone types.

Our work differed from that of Lima and Ranieri (2018) because it studied documentary based only on one type of zone with specific characteristics. Zhang et al. (2013) presented a similarity in the sense of combining methodologies (e.g., GIS and multi-criterion analysis), although they used previous knowledge, which is difficult for research in Brazil because many units do not have the minimum mandatory document that is the management plan. Vardarman et al. (2018) developed a method of zoning by observing biological factors like the invasion of exotic species resembling the variable regeneration treated in this model. It is difficult within the context of conservation to say which methodology is the best because each area has its particularity. The variables are chosen according to specificity of the area, making it difficult to compare approaches. Territorial zoning is undeniably difficult, even with its limitations, yet it reduces the external impact on the area (Bruggeman et al., 2015).

The high variation of the model classification occurred because during reforestation in the case study area, the natural distribution of the species was not observed. The area was divided in fields, where in some cases, a single species or a combination of two or three species were planted without criterion. Therefore, the interpolation method cannot understand the characteristic of the area that is extremely particular. In areas where the vegetation change is not as abrupt as natural areas, this variation tends to be very small because the neighborhood of the studied site will have similar characteristics.

The model proposed herein showed that zoning classification can be done in a standardized and simplified manner, as suggested by Lin and Li (2016), because traditional models are complex to use and interpret.

In the case of zoning, this classification may encounter different interests with different stakeholders perceiving different versions of the same problem. In this context, the implantation of an ecological park, for example, can have a double understanding. Those interested in installing the park may want to enter the natural areas, which contradicts the conservationist interests of maintaining the intangibility of a core area. In this sense, approaches that consider transition zones present more information for decision makers, and can be interpreted as a buffer for the possible damages on the intangible and natural areas, that is, work as attenuating human intervention, for example (Liu and $\mathrm{Li}, 2008$ ).

Zoning is indispensable in decision making in a conservation area, and studies of possible reproduction and understanding are valued (Cook et al., 2012). The obtained results allowed for an adequate management of each class according to its peculiarity. When transition areas are included in the classification, the knowledge of their size and location can contribute to the management of the area, thereby allowing greater care with areas that already belong to a more restrictive level, but with a small degree of pertinence.

Many preservation areas in Brazil still do not have a management plan even with numerous documents and studies that confirm the importance of zoning. The management plan has been defined since 1979 and is a mandatory document since 2002, and an integral part of this document is zoning. The preservation areas that have this territorial order do not explain the methodology to generate the territorial classification (Ministério do Meio Ambiente, 2011).

Liu and Li (2008) argued that problems with the implementation of zoning schemes in China and elsewhere include the lack of clear regulations on how to structure the spatial arrangement of zones and the lack of guidelines that determine what factors should be 
considered. Many variables are treated and considered in Brazilian laws that define zoning in preservation areas; however, we chose to deal with vegetation because if vegetation is not in a favorable state, the fauna will also not find survival conditions. The choice permitted the use of classic vegetation indexes in the literature, such as EVI, which made the model very practical. Lin et al. (2018) compared the performance of some strategies used to evaluate areas that should be retained. The authors pointed out that unfortunately, selecting the most appropriate model is often difficult because of limited data and knowledge.

However, one of the advantages of the methodology proposed herein is the standardization in the territorial planning of preservation areas in the Atlantic Forest, and the particularity of each study area may be adequate. If an area has potential for visitation, a human intervention variable can be included. If the study area is another type, the rules of this model can be adapted to classify and describe the reality of that place.

\section{Conclusions}

The whole area under study can be covered during sampling. Moreover, with the experience acquired, the presented results can more adequately describe the studied area. We presented herein a new methodological proposal for PA zoning. The PA classification presents a systematization to the process of territorial planning with input variables having quantitative and qualitative parameters, which allows an approximation of the reasoning of specialists obtaining a numerical result easy to classify in the zones as established in the National System of Nature Conservation Units. The model provides methods of automating decisions based on fuzzy logic. This methodology is promising because it can be used automatically and independently. It also allows adaptation to any PA because it meets the law requirements. The intersections between the fuzzy set output will be areas of special attention because being in an intermediate stage, the management of this area can be improved for insertion into a category of greater preservation.

This model introduces a tool that can be used to review and monitor the zoning of protected areas that the legislation has defined to be periodically reviewed. In practice, the model offers zoning in which the spatial division presents no rigid limits, but rather flexible boundaries to the real objective of the area, thereby providing the manager with detailed spatial classification maps that can be used to plan impediments and permissions for the proper management of the area.

Future studies can work on the insertion of new variables. For example, in open areas to visitation, the variable "human intervention" can be inserted to verify the degree of impact of human action, qualifying factors as the presence of garbage, fires, tree cuttings, and signs of hunting, among others. For example, we can compare the model performance of areas with different characteristics including characteristics other than reforestation.

\section{REFERENCES}

[1] Atzberger, C. (2013): Advances in remote sensing of agriculture: Context description, existing operational monitoring systems and major information needs. - Remote Sensing 5(2): 949-981.

[2] Azevedo-Santos, V. M., Fearnside, P. M., Oliveira, C. S., Padial, A. A., Pelicice, F. M., Lima Jr, D. P., Simberloff, D., Lovejoy, T. E., Magalhães, A. L. B., Orsi, M. L., Agostinho, A. A., Pompeu, P. S., Laurance, W. F., Petrere Jr, M., Mormul, R. P., Vitule, J. R. S. (2017): 
Removing the Abyss between Conservation Science and Policy Decisions in Brazil. Biodiversity Conservation 26: 1745-1752.

[3] Bernard, E., Penna, L. A. O., Araújo, E. (2014): Downgrading, Downsizing, Degazettement, and Reclassification of Protected Areas in Brazil. - Conservation Biology 28(4): 939-50.

[4] Bruggeman, D., Meyfroidt, P., Lambin, E. F. (2015): Production Forests as a Conservation Tool : Effectiveness of Cameroon's Land Use Zoning Policy. - Land Use Policy 42: 15164.

[5] Chen, G., Pham, T. T. (2000): Introduction to Fuzzy Sets, Fuzzy Logic and Fuzzy Control Systems. - CRC Press, Florida.

[6] Cook, C. N., Carter, R. W. B., Fuller, R. A., Hockings, M. (2012): Managers consider multiple lines of evidence important for biodiversity management decisions. - Journal of Environmental Management 113: 341-346.

[7] Fendrich, A. N., Rocha, A. G., Ranieri, V. E. L. (2019): Comparison between official priority studies guidelines and Protected Areas created in Brazil. - Land Use Policy 82: 240-246.

[8] Gomide, F., Gudwin, R. (1994): Modelagem, Controle, Sistemas e Lógica Fuzzy. - SBA Controle \& Automação 4(3): 97-115.

[9] Hsueh, S. L., Cheng, A. C. (2017): Improving air quality in communities by using a multicriteria decision-making model based on big data: A critical review. - Applied Ecology and Environmental Research 15(2): 15-31.

[10] IBAMA. Instituto Brasileiro do Meio Ambiente e dos Recursos Naturais Renováveis (2002): Roteiro metodológico de planejamento: Parque Nacional, Reserva Biológica e Estação Ecológica. - IBAMA, Brasília.

[11] IBGE. Instituto Brasileiro de Geografia e Estatística (2012): Manual Técnico da Vegetação Brasileira. - IBGE, Brasília.

[12] IBGE. Instituto Brasileiro de Geografia e Estatística (2015): Indicadores de Desenvolvimento Sustentável.

[13] IBGE. Instituto Brasileiro de Geografia e Estatística (2019): Áreas de Municipios. https://goo.gl/Y836Js.

[14] Ibrahim, A. M. (2004): Fuzzy Logic for Embedded Systems Applications. - Newnes, Burlington.

[15] Jenkins, C. N., Joppa, L. (2009): Expansion of the global terrestrial protected area system. - Biological Conservation 142(10): 2166-2174.

[16] Jensen, J. R. (2009): Remote Sensing of the Environment: A perspective on land resources. - Parêntese, São José dos Campos.

[17] Jim, F., Mart, C. (2019): Multi-Objective Evolutionary Feature Selection for Fuzzy Classification. - IEEE Transactions on Fuzzy Systems 6706(c): 1-15.

[18] Kennedy, D. (2007): Sustainability. - Science 315(5812): 573.

[19] Lima, E. A. C. F., Ranieri, V. E. L. (2018): Land Use Planning around Protected Areas: Case Studies in Four State Parks in the Atlantic Forest Region of Southeastern Brazil. Land Use Policy 71: 453-58.

[20] Lin, J., Li, X. (2016): Conflict Resolution in the Zoning of Eco-Protected Areas in FastGrowing Regions Based on Game Theory. - Journal of Environmental Management 170: 177-185.

[21] Lin, Y. P., Lin, W. C., Anthony, J., Ding, T. S., Mihoub, J. B., Henle, K., Schmeller, D. S. (2018): Assessing uncertainty and performance of ensemble conservation planning strategies. - Landscape and Urban Planning 169: 57-69.

[22] Liu, X., Li, J. (2008): Scientific solutions for the functional zoning of nature reserves in China. - Ecological Modelling 215: 237-246.

[23] Management Plan. (2010): Plano De Manejo Área de Relevante Interesse Ecológico Santa Helena. - Nattural Engenharia Ambiental, Santa Helena. 
[24] Mazza, C. A. S., Mazza, M. C. M., Almeida, D., Santos, J. E., Fushita, A. T. (2016): Land Use and Environmental Zoning of Mixed Ombrophilous Forests for Sustainable Use (Irati National Forest, Brazil Southern Region). - Brazilian Archives of Biology and Technology 59: $1-11$.

[25] Ministério do Meio Ambiente. (2011): SNUC. - Sistema Nacional de Unidades de Conservação da Natureza: Lei no 9.985, de 18 de julho de 2000; Decreto no 4.340, de 22 de agosto de 2002; Decreto no 5.746, de 5 de abril de 2006. Plano Estratégico Nacional de Áreas Protegidas: Decreto no 5.758, de 13 de abril de 2006. https://goo.gl/V6ZNVJ.

[26] Moilanen, A., Wilson, K. A., Possingham, H. P. (2009): Spatial Conservation Prioritization: Quantitative Methods and Computational Tools. - Oxford University Press, Oxford.

[27] Muller-Dombois, D., Ellenberg, H. (1974): Aims and Methods of Vegetation Ecology. John Wiley \& Sons, New York.

[28] Munda, G., Nijkamo, P., Rietveld, P. (1994): Qualitative Multicriteria Evaluation for Environmental Management. - Ecological Economics 10: 97-112.

[29] Myers, N., Mittermeier, R. A., Mittermeier, C. G., Fonseca, G. A. B., Kent, J. (2000): Biodiversity hotspots for conservation priorities. - Nature 403(6772): 853-858.

[30] Oliveira, J. H. A. (1999): Lógica Difusa: Aspectos Práticos e Aplicações. - Interciência, Rio de Janeiro.

[31] Rezende, S. O. (2005): Sistemas Inteligentes - Fundamentos e Aplicações. - Manole, Barueri, São Paulo.

[32] Sheehan, T., Gough, M. (2016): A platform-independent fuzzy logic modeling framework for environmental decision support. - Ecological Informatics 34: 92-101.

[33] Shepard, D. (1968): A two-dimensional interpolation function for irregularly-spaced data. - Proceedings of the 1968 23rd ACM National Conference: 517-524.

[34] Simardi, V., Souza, B. (2018): Tourism Demand Analysis of the Federal Protected Areas of Brazil. - Journal Park Recreation Administration 36: 1-22.

[35] Todorov, V., Marinova, D. (2011): Modelling sustainability. - Mathematics and Computers in Simulation 81: 1397-1408.

[36] USGS. United States Geological Survey (2017): Product Guide Landsat surface Reflectance-Derived Spectral Indices. - USGS, Washington.

[37] Vardarman, J., Berchová-Bímová, K., Pěknicová, J. (2018): The Role of Protected Area Zoning in Invasive Plant Management. - Biodiversity and Conservation 27(8): 1811-1829.

[38] Watson, J. E. M., Dudley, N., Segan, D. B., Hockings, M. (2014): The Performance and Potential of Protected Areas. - Nature 515: 67-73.

[39] Zadeh, L. A. (1965): Fuzzy Sets. - Information and Control 353: 338-353.

[40] Zhang, Z., Sherman, R., Yang, Z., Wu, R., Wang, W., Yin, M., Yang, G., Ou, X. (2013): Integrating a Participatory Process with a GIS-Based Multi-Criteria Decision Analysis for Protected Area Zoning in China. - Journal for Nature Conservation 21(4): 225-40. http://dx.doi.org/10.1016/j.jnc.2012.12.006.

[41] Zimmermann, H. J. (2001): Fuzzy set theory - and its appications. - Springer Science LLC, New York. 


\section{APPENDIX}

\section{Coordinates:}

\begin{tabular}{|c|c|c|}
\hline \multicolumn{3}{|c|}{$\begin{array}{c}\text { Coordinates in the Universal Transverse Mercator (UTM) projection zone 21S and WGS } 84 \text { (World Geodetic } \\
\text { System 84) ellipsoid. }\end{array}$} \\
\hline Point & longitude & latitude \\
\hline 1 & 767209 & 7251377 \\
\hline 2 & 766778 & 7251376 \\
\hline 3 & 766162 & 7251118 \\
\hline 4 & 766501 & 7250791 \\
\hline 5 & 765779 & 7250325 \\
\hline 6 & 765280 & 7249668 \\
\hline 7 & 765747 & 7249377 \\
\hline 8 & 766461 & 7249379 \\
\hline 9 & 766466 & 7249388 \\
\hline 10 & 767971 & 7250740 \\
\hline 11 & 768107 & 7250908 \\
\hline 12 & 768241 & 7251278 \\
\hline 13 & 767098 & 7250960 \\
\hline 14 & 767104 & 7250496 \\
\hline 15 & 767327 & 7250269 \\
\hline 16 & 767028 & 7250243 \\
\hline 17 & 766827 & 7250542 \\
\hline 18 & 767312 & 7251509 \\
\hline 19 & 767369 & 7251962 \\
\hline 20 & 767385 & 7252360 \\
\hline 21 & 766053 & 7250987 \\
\hline 22 & 766649 & 7251414 \\
\hline 23 & 767101 & 7251257 \\
\hline 24 & 767447 & 7252459 \\
\hline 25 & 767634 & 7252816 \\
\hline 26 & 767799 & 7252901 \\
\hline 27 & 768540 & 7253207 \\
\hline 28 & 768633 & 7253195 \\
\hline 29 & 768741 & 7252997 \\
\hline 30 & 768803 & 7252822 \\
\hline 31 & 768494 & 7252703 \\
\hline 32 & 768162 & 7252579 \\
\hline 33 & 768270 & 7253055 \\
\hline 34 & 767436 & 7249342 \\
\hline 35 & 766973 & 7249448 \\
\hline 36 & 766627 & 7249622 \\
\hline 37 & 767113 & 7249927 \\
\hline 38 & 767630 & 7249576 \\
\hline 39 & 767917 & 7249943 \\
\hline 40 & 767916 & 7250327 \\
\hline 41 & 767626 & 7250008 \\
\hline 42 & 766624 & 7250176 \\
\hline 43 & 766810 & 7253571 \\
\hline 44 & 766837 & 7254195 \\
\hline 45 & 766814 & 7254640 \\
\hline 46 & 766679 & 7254946 \\
\hline 47 & 766290 & 7254799 \\
\hline 48 & 766031 & 7254491 \\
\hline 49 & 766287 & 7254256 \\
\hline 50 & 766436 & 7253945 \\
\hline 51 & 766251 & 7253683 \\
\hline 52 & 766214 & 7253284 \\
\hline
\end{tabular}




\begin{tabular}{|c|c|c|}
\hline \multicolumn{3}{|c|}{$\begin{array}{l}\text { Coordinates in the Universal Transverse Mercator (UTM) projection zone 21S and WGS } 84 \text { (World Geodetic } \\
\text { System 84) ellipsoid. }\end{array}$} \\
\hline Point & longitude & latitude \\
\hline 53 & 766639 & 7255076 \\
\hline 54 & 766707 & 7255565 \\
\hline 55 & 766435 & 7255773 \\
\hline 56 & 766298 & 7256113 \\
\hline 57 & 766440 & 7256570 \\
\hline 58 & 766708 & 7256859 \\
\hline 59 & 767215 & 7256764 \\
\hline 60 & 767391 & 7256276 \\
\hline 61 & 767554 & 7255888 \\
\hline 62 & 767721 & 7255495 \\
\hline 63 & 767517 & 7255290 \\
\hline 64 & 767628 & 7255060 \\
\hline 65 & 767764 & 7254750 \\
\hline 66 & 768007 & 7254634 \\
\hline 67 & 767736 & 7254358 \\
\hline 68 & 767561 & 7253874 \\
\hline 69 & 767596 & 7253409 \\
\hline 70 & 766467 & 7249868 \\
\hline 71 & 765194 & 7249443 \\
\hline 72 & 767238 & 7253017 \\
\hline 73 & 766884 & 7253348 \\
\hline 74 & 766828 & 7253100 \\
\hline 75 & 766827 & 7252735 \\
\hline 76 & 766834 & 7252429 \\
\hline 77 & 766834 & 7251943 \\
\hline 78 & 767009 & 7251743 \\
\hline 79 & 766349 & 7251242 \\
\hline 80 & 765967 & 7250650 \\
\hline 81 & 765462 & 7250222 \\
\hline 82 & 768641 & 7253572 \\
\hline 83 & 768307 & 7253487 \\
\hline 84 & 768012 & 7252424 \\
\hline 85 & 767999 & 7251938 \\
\hline 86 & 767931 & 7251239 \\
\hline 87 & 767573 & 7251373 \\
\hline
\end{tabular}

